\title{
Default patterns of patients attending clinics for sexually transmitted diseases
}

\author{
J. D. H. MAHONY, JOHN ${ }_{i}$ BEVAN, AND BARBARA WALL \\ From St Giles' Hospital, London, and the Health Services Research Unit, \\ University of Kent at Canterbury
}

SUMMARY The influence of gender, propaganda, and treatment methods was studied in relation to default behaviour of patients with sexually transmitted diseases. The overall default rate of men and women was similar, but a larger proportion of men defaulted after the initial visit, while the biggest fall-out in women was after the second attendance at the clinic. The institution of a propaganda campaign was followed by a reduction in defaulting. The statistical significance of this is open to question, however: moreover the observed improvement in default rate was not maintained once the propaganda had been relaxed. Men treated for non-gonococcal urethritis by a regimen which included one injection a week for three weeks showed a highly significantly lower default rate compared with those who received tablets alone.

\section{Introduction}

The term 'defaulter' is well recognised in clinics dealing with sexually transmissible diseases. Although it is impossible to give a scientifically precise definition of this term, it has real meaning for venereologists and seems, despite its quasimilitary associations, to be preferable to the term 'patient drop-out'. In a comprehensive review article, Blackwell (1976) uses the terms 'patient compliance' and 'patient adherence', but he uses them with special reference to treatment schedules rather than for routine follow-up attendances. He makes the point that the word 'compliance' has no counterpart in the German or Dutch languages. Venereologists are just as interested in 'treatment adherence' as any other doctor who prescribes treatment, but their primary aim must be to prevent default since a high default rate precludes an accurate estimation of either treatment adherence or therapeutic response. Hewitt (1969) devised an ingenious formula for assessing therapeutic response which took into account those patients who had defaulted after treatment for gonorrhoea, but it seems preferable to make a therapeutic estimate solely by assessing those patients who do not default. It is desirable to adopt any measures that reduce the default rate, since the lower this is, the more valid are the conclusions arising from any assessment of treatment.

Address for reprints: J. D. H. Mahony, MD, FRCP, Consultant Venereologist, St Giles' Hospital, St Giles' Road, London SE5 7RN Received for publication 2 August 1977

\section{Patients and methods}

\section{PATIENTS}

Men v. women (Group A patients)

The first part of the study was carried out on all patients attending the sexually transmitted disease clinic at the Kent and Canterbury Hospital from 1 January to 30 June 1975 . This comprised 224 men and 139 women. In this instance, a defaulter was defined as a patient who was judged to have failed, of his or her own volition, to complete the period of supervision, usually three months, recommended by the doctor at the first interview. (This rather imprecise definition is applicable only to Group A and Group $C$ patients.) In the rest of the study the one- and two-attendance default rate-a more precisely measurable parameter-is considered.

\section{Effect of propaganda and intensive counselling} (Group B patients)

A comparative study was made on one- and twoattendance default rate of 53 men with gonorrhoea who attended the Alexanda Clinic at St Giles' Hospital in July 1975, and 45 men with gonorrhoea who attended the clinic in July 1976. Those attending in July 1976 were subjected to intensive exhortation and counselling by medical and nursing staff at their first visit. The importance of remaining under surveillance was stressed and verbal advice was reinforced with posters displayed in the waiting room and reception areas. 
A parallel study was also carried out between men with non-gonococcal urethritis (NGU) who attended St Giles' Hospital in July 1975 and July 1976.

Exhortation and counselling were reduced to normal levels in August 1976 and the one- and two-attendance default rates of patients with gonorrhoea were again analysed.

Finally, the combined one- and two-attendance default rate for men with gonorrhoea, plus men with NGU for July 1976, was compared with that for July 1975.

\section{Effect of treatment schedules (Group C patients)}

These comprised 217 men who had taken part in a combined clinical trial between St Giles' Hospital and the Kent and Canterbury Hospital from January to December 1974.

Two treatment schedules for NGU had been compared for therapeutic efficiency and influence on default rate. One regimen consisted of three injections of streptomycin sulphate $(1 \mathrm{~g}$ intramuscularly) given at weekly intervals. This was combined with a simultanous oral dose of $2 \mathrm{~g}$ of the ultra long-acting sulphonamide, sulfametopyrazine (Kelfizine). The other regimen consisted of administering an oral dose of one tablet of the triple tetracycline, Deteclo, twice a day for three weeks. These patients were asked to report weekly for the next two weeks and, thereafter, at prescribed intervals for a total of 12 weeks.

\section{FACTORS THAT MAY INFLUENCE DEFAULT RATES}

The factors with a possible influence on default rates considered in this study were:

Gender of the patient (male or female)

Propaganda and counselling

Treatment methods

The effect of sending 'default letters' or reminders to patients who had not kept their appointments was also assessed for Group A patients.

\section{Results}

MEN V. WOMEN

Table 1 Overall default rate at Kent and Canterbury Hospital

\begin{tabular}{ll}
\hline Men & Women \\
\hline$\frac{122}{224}=54.5 \%$ & $\frac{68}{139}=48.9 \%$ \\
\hline
\end{tabular}

Table 1 shows that there was little difference between the overall default rates of men and women in the patients attending Kent and Canterbury Hospital (January to June 1975).

Table 2 Proportion of total defaulters after first two attendances at Kent and Canterbury Hospital

\begin{tabular}{lll}
\hline Defaulters & Men & Women \\
\hline After one visit & $\frac{41}{122}=33.6 \%$ & $\frac{16}{68}=23.5 \%$ \\
After two visits & $\frac{28}{122}=23.0 \%$ & $\frac{27}{68}=39 \cdot 7 \%$ \\
Others & $\frac{53}{122}=43.4 \%$ & $\frac{25}{68}=36.8 \%$ \\
\hline & $\chi_{2}{ }^{2}=6 \cdot 2 ; \mathrm{P}<0.05$
\end{tabular}

The results suggest that one-third of men who default do so after the first attendance, whereas less than one-quarter of women who default cease to att nd at this stage (Table 2). On the other hand, nearly $40 \%$ of women who default do so after the second attendance, whereas less than one-quarter of the male defaulters cease attending after this attendance. The total default rate after the first two visits is similar for both sexes and comprises more than half of the total default rate.

The response rate to 'default letters' sent to patients who had missed an appointment was poor for both sexes. A total of 93 default letters were sent to the 122 men and there was no response in $81(87 \%)$ of these. An almost identical 'non-response rate' of $86 \%$ was obtained from the women. These results include a small proportion of patients of either sex who were sent more than one letter.

EFFECT OF PROPAGANDA AND INTENSIVE COUNSELLING

Table 3 Gonorrhoea in men (St Giles' Hospital)

\begin{tabular}{lll}
\hline Rate of defaults & July 1975 & July 1976 \\
\hline After one visit & $\frac{16}{53}=30.2 \%$ & $\frac{8}{45}=17.8 \%$ \\
After two visits & $\frac{19}{53}=35.9 \%$ & $\frac{9}{45}=20 \%$ \\
\hline & $\chi_{2}^{2}=7.8 ; \mathrm{P}<0.025$
\end{tabular}

The intensive patient counselling carried out in the clinic in July 1976 did appear to have a statistically significant effect in reducing both the one- and two-attendance default rates, see Table 3 . However, this impression is unduly flattering to the results achieved by propaganda and counselling: for although it is true that the default rate for July 1976 was lower than that for the other three months $(38 \%$ 
compared with $66 \%, 48 \%$, and $52 \%$ ), the decrease is not significant when compared with August 1975 and August 1976. One suspects that defaulting in July 1975 was, for some reason, abnormally high, and that this made the results for July 1976 seem better than they in fact were.

The same restrictions must also apply when interpreting Tables 4, 5, and 6.

Table 4 Gonorrhoea in men (St Giles' Hospital)

\begin{tabular}{lll}
\hline Rate of defaults & August 1975 & August 1976 \\
\hline After one visit & $\frac{10}{56}=17 \cdot 9 \%$ & $\frac{13}{66}=19 \cdot 7 \%$ \\
After two visits & $\frac{17}{56}=30 \cdot 4 \%$ & $\frac{21}{66}=31 \cdot 8 \%$ \\
\hline
\end{tabular}

Table 5 Non-gonococcal urethritis in men (St Giles' Hospital)

\begin{tabular}{lll}
\hline Rate of defaults & July 1975 & July 1976 \\
\hline After one visit & $\frac{18}{75}=24 \cdot 0 \%$ & $\frac{16}{9}=16.8 \%$ \\
After two visits & $\frac{25}{75}=33.3 \%$ & $\frac{23}{95}=24.2 \%$ \\
\hline & $\chi_{2}^{2}=4.5 ; 0.20>\mathrm{P}>0.10$
\end{tabular}

Table 6 Gonorrhoea and non-gonococcal urethritis in men (St Giles' Hospital)

\begin{tabular}{lll}
\hline Rate of defaults & July 1975 & July 1976 \\
After one visit & $\frac{34}{128}=26 \cdot 6 \%$ & $\frac{24}{140}=17 \cdot 1 \%$ \\
After two visits & $\frac{44}{128}=34 \cdot 4 \%$ & $\frac{32}{140}=22.9 \%$ \\
\hline & $\chi_{2}^{2}=11 \cdot 7 ; \mathrm{P}<0.01$
\end{tabular}

Normal patient counselling was resumed in August 1976 and the results show that the default rates were similar to those of the previous year.

The reduction in one- and two-attendance default rates for men suffering from NGU was also in response to the propaganda and counselling efforts of July 1976, although not to as marked a degree as had been the case with gonorrhoea.

A possible explanation of the difference could be that gonorrhoea is regarded as more serious than NGU, not only by the patient, but also by the doctor who may therefore not emphasise the importance of continued surveillance with the same conviction as he would when dealing with gonorrhoea.
It can be seen that the propaganda and counselling programme of July 1976 reduced the one- and two-attendance default rates for the sum of patients with gonorrhoea plus patients with NGU convincingly and apparently significantly: but it must be borne in mind (vide supra) that the default rate for July 1975 was abnormally high and so tended to exaggerate the apparent benefit of combined counselling and propaganda in July 1976.

\section{EFFECT OF TREATMENT SCHEDULES ON DEFAULTING}

NGU trial: Kent and Canterbury Hospital and St Giles' Hospital, June to December 1974

In this therapeutic trial using two different treatments for NGU as outlined above, an interesting and unexpected finding was that the default rate in the group having weekly injections was $16.7 \%$ of 108 patients and significantly lower than in the group given oral treatment alone $(33 \%$ out of 109).

$$
\chi_{1}^{2}=7 \cdot 1 ; \mathbf{p}<0.01
$$

\section{Discussion and conclusions}

The results show that the most likely time for men to default is after the first visit, whereas women tend to 'drop out' after the second clinic attendance (Table 2). The likely explanation is that most men come to a clinic because of symptoms, whereas most women are asymptomatic at the first visit (Mahony, 1972). Men therefore tend to cease attending when symptoms clear up which is very often after taking the treatment given to them at the first visit. Women, however, have to rely for reassurance on receiving the results of bacteriological cultures which are not available until they attend the clinic for a second time. Table 2 also shows that more than half of men and women who default do so after only two attendances at the clinic. Since the response to default letters is poor (less than $15 \%$ positive response in both sexes), it follows that propaganda must be given at the clinic at the first and second visit. Tables 3,5 , and 6 show that such propaganda can be effective, but it has to be sustained or the defaulter rate soon reverts to the previous level (Table 4).

Moreover the results were not as good, for reasons already given, as Tables $3,4,5$, and 6 seem to suggest. It must be concluded that counselling and propaganda, like all types of health education, do not achieve quick results, and need to be maintained to be effective.

Finally, it was found that by instructing patients to return to the clinic, not just for review and 
assessment but for the specific purpose of having an injection, the default rate was significantly reduced. Since the therapeutic efficiency of both regimens (with or without an injection) was similar, it was surmised that patients were motivated to attend when treatment was valued more highly, and that injections appeared to be valued more than tablets. This point requires further elucidation and a trial with randomly allocated placebo injections is currently under way.

Our sincere thanks are due to Professor Michael Warren, Director of the Health Services Research Unit at the University of Kent at Canterbury, for his advice in designing the questionnaire employed at the Kent and Canterbury Hospital. (Default behaviour was only one facet of a comprehensive study for which the questionnaire was designed. Professor Warren's department processed the results obtained for computer analysis.)
Our thanks are also due to Mrs Sheila Baugh, secretary, and Mrs Yvonne Reeves, health worker to the Special Clinic of the Kent and Canterbury Hospital, for their help in compiling the results obtained from the questionnaire.

We would also like to thank Sister Elizabeth Schofield of St Giles' Hospital for searching the records of the Special Clinic at that hospital, and Dr Richard Hallam of the Faculty of Human Sciences in the Department of Psychology at the North East London Polytechnic who helped with statistical analysis of the results.

\section{References}

Blackwell, B. (1976). Treatment adherence. British Journal o Psychiatry, 129, 513-531.

Hewitt, A. B. (1969). Significance of the 'defaulter' in the assessment of efficiency of treatment in gonorrhoea. British Journal of Venereal Diseases, 45, 40-41.

Mahony, J. D. H. (1972). Analysis of attendance motivation in a Belfast venereal diseases clinic. British Journal of Venereal Diseases, 48, 71-74. 